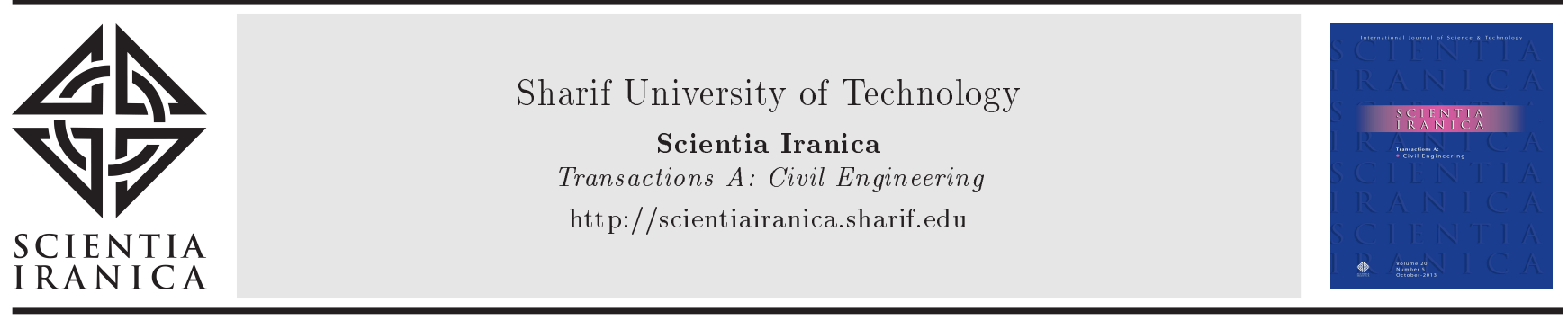

\title{
Online seismic database with seismological and structural parameters
}

\author{
A. Catalan ${ }^{\mathrm{a}}$, D. Foti ${ }^{\mathrm{b}, *}$, and D. Melendi ${ }^{\mathrm{c}}$ \\ a. Department of Construction, University of Oviedo, Campus of Gijon, Calle Luis Ortiz Berrocal s/n, 33203 Gijon, Spain. \\ b. Department of Civil Engineering and Architecture, Polytechnic University of Bari, Via Orabona 4, 70125 Bari, Italy. \\ c. Department of Informatics, University of Oviedo, Campus of Gijon, Calle Luis Ortiz Berrocal s/n, 33203 Gijon, Spain.
}

Received 5 February 2017; received in revised form 11 May 2017; accepted 15 July 2017

\section{KEYWORDS}

Seismic database;

Selection of records;

PBEE;

Engineering

parameters;

Strong ground motion.

\begin{abstract}
In this paper, a new free online seismic database is presented. The database has 15 seismological and 26 deducted engineering parameters to search for available records for structural seismic analysis. As known, the selection and scaling of seismic records acquire primary importance in seismic analysis. Moreover, the application and development of Performance-Based Earthquake Engineering (PBEE) implies finding records in different levels of the return period. This is a time-consuming and cumbersome procedure and the whole process is affected by great randomness. A database with specific parameters that permits finding best suited records would prove very useful. As a consequence, the randomness both in the seismic action and in the results of the dynamic behavior of the structure can be strongly reduced. This is the objective of the new database. In this work, the authors describe the new database and develop a numerical application with 3 different bins of parameters of selection for records and results of structural analyses. The great usefulness of the database is shown.
\end{abstract}

(C) 2019 Sharif University of Technology. All rights reserved.

\section{Introduction}

Currently, the tendency in structural seismic calculus is moving from analyses towards nonlinear temporary development with the use of records (temporary signals). Traditionally, records of various precedence (real, synthetic, and artificial records) have been used.

In the past, when real or actual records (from seismic stations and real earthquakes) were scarce, the elaboration of complementary records was necessary to complete the catalogs of possible records for a structure, i.e., synthetic and artificial records were required. Nowadays, abundant catalogs of real records exist. At

\footnotetext{
*. Corresponding author. Tel.: +39 3201710524; Fax: +39080 5963719

E-mail address: dora.foti@poliba.it (D. Foti)
}

present and in the future, the tendency of seismic standard is to use only real records. For example, the FEMA P695 [1], as indicated in point 6 and Appendix A of the standard itself, in a clear way postulates the use of real records with a minimum of over 20 records ( 2 horizontal components), which necessitates the development of a database. Also, the new ASCE716 [2] requires the use of these records. Although all codes still permit the use of artificial records, it is unacceptable today to make use of artificial or synthetic records for responses history analysis of structures.

Real records are the most suitable ones, because they incorporate the characteristic uncertainties of the seismic signal (record-to-record variability). In spite of the large earthquakes we have faced in recent years, in some seismic zones, the records of high magnitude continue to be scarce. Notwithstanding, there are available records that can be used without difficulty, still when they belong to different seismic zone. 
Several seismic databases of records have been created and many of them are available through free access; these records can be utilized in structural design calculus. Very important elaborated public databases exist online (PEER, IRIS, COSMOS, CESMD, KNET/KIK-NET, EUROSEISTEST, IESEE, SGMDT, SWISS NSNM, ITACA, NERA, USGS) [3-14]. Recently, in Europe, an excellent work was carried out through the ORFEUS-ESM European Strong Motion Database Project [15]. All of the above-mentioned databases permit obtaining records with appropriate searching with regards to seismologic parameters (i.e., magnitude, epicentral distance, fault mechanism type, soil type, PGA, PGV, PGD, duration, etc.) and some engineering parameters $\left(S_{a}, S_{v}, S_{d}\right.$, spectral characteristics, etc.).

Some of these databases permit finding a group of records, using their median, and making them compatible with an indicated reference spectral target. Extensive graphics in linear, semi-log, or log-log form can be found. The spectra of records are scaled in order to achieve compatibility with the referential spectrum (usually, standard target spectrum). It is the usual calculation procedure when multiple records are available in a nonlinear structural analysis of probabilistic type, which makes their application easier.

Two well established concepts in the scientific community are generally utilized in seismically calculating the structures: On the one hand, PerformanceBased Earthquake Engineering (PBEE) is applied [1618] with different levels of calculus from different levels of earthquake (return period) with established damages correlating to each other; on the other hand, the excellent conceptual frame of PEER [19] is considered, where a sequence $I M-E D P-D M-D V$ is indicated for each adopted level. Here, $I M$ denotes an intensity measure, EDP denotes engineering demand parameters, $D M$ denotes damage measures, and $D V$ denotes decision variables.

The problem faced when applying PBEE is that this approach needs real records for different levels of intensity [20,21].

From the statistical point of view, a fixed amount of records for each level is necessary. The problem becomes more intense at low-to-moderate seismic zones, where enough records do not exist. It is noteworthy that the PBEE methodology is completely applicable in low-to-moderate seismic zones and that earthquakes of minor magnitude (minor hazard) do not imply lower seismic risk, as structures are calculated for the low-magnitude earthquakes. The records adequately corresponding to the applied levels of PBEE should be sought.

Therefore, it is important to have a database that can also be successfully utilized for PBEE approaches. The selection of the Intensity Measure $(I M)$ is im- portant in the search and selection of records. Any parameter that is used to select records $(I M)$ has a very important implication in post-processing.

It must be taken into account which parameters have higher influence on the structural behavior, i.e., reliability and dispersion (correlation) with the results found in the structural analysis for a selected $E D P$. These $I M s$ are of the seismologic-like structural type, so it is important when to choose the records to utilize (in the selection and scaling). This is where a database proves to be more useful, since it provides the possibility to jointly combine vectors that simultaneously take into account two types of IMs.

In this paper, an accessible online seismic database is proposed. The database makes use of different parameters for searching for records, taking the previous comments into account. An overview of the database characteristics and development is provided in the first part of the paper. Next, a simple real application for searching for records of seismic calculations of structures is presented. Finally, the benefits of the use of this database and its possible improvements are discussed.

\section{Database description}

The seismic database belongs to the University of Oviedo (Asturias, Spain). Its development and characteristics are highlighted in the flowchart of Figure 1. The name of the database is Seismic Analysis System (SAS) [http://www.dbseismic.uniovi.es]. Anonymous access is free for downloading only 10 records. Records have been extracted from other public databases and collected in SAS database; they are respectively mentioned in sources. Always, corrected records (filtered and line base corrected) are utilized.

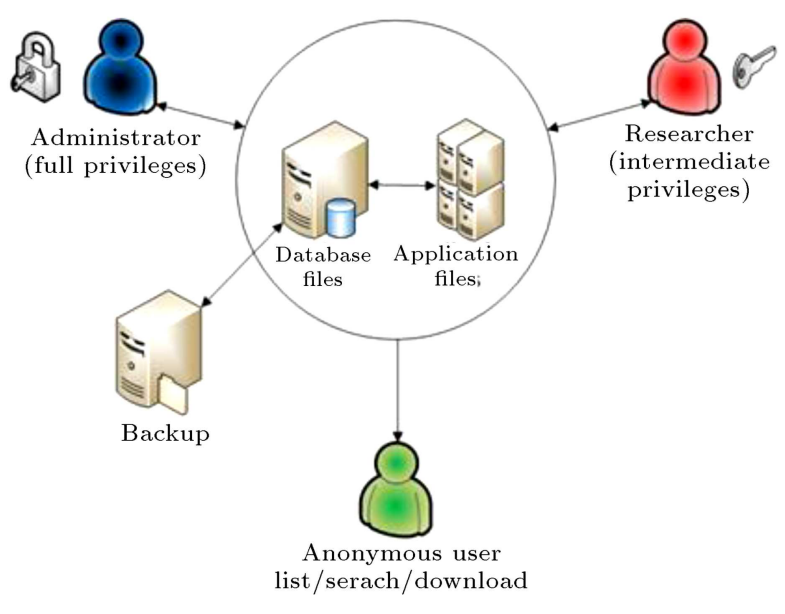

Figure 1. Flowchart of database implementation. Users types: anonymous, registered (researcher), and administrator users. Database files: application files and backup system. 
The database is completely accessible via the web and it is possible to upload earthquake records, consult, search for the desired records, and download records of interest. The records have searching fields of seismologic and engineering types, as mentioned before. For each record, there are a total of 41 fields, with 15 seismologic and 26 engineering parameters.

Basically, earthquakes are uploaded with their fundamental seismic data (name, time, depth, magnitude, etc.); then, the records associated with accelerograms are uploaded (with the basic seismologic parameters of epicentral distance, soil type station, duration, etc.); and finally, all the engineering parameters deduced from system or application files are found $\left(S_{a}\right.$, $S_{v}, S_{d}, \mathrm{AI}$, etc.). The $5 \%$ damped value is used in all spectra. In the end, the records defined with 41 fields allow for various crossed searching and selection according to the judgment of the user. Appendix A provides all the basic information, such as the parameter list utilized, and the definitions with specific references.

The actual records uploaded to the database were obtained from the database of European earthquakes [22]. This database contains 462 records (1386 accelerograms) of magnitudes ranging from $M=3$ to $M=6$ and epicenter distances from $\Delta=12 \mathrm{~km}$ to $\Delta=500 \mathrm{~km}$. This is a low-to-moderate magnitude range. At present, SAS database has 110 earthquakes and 1013 records of three components.

Regarding the system specifications and software programming characteristics, WAMP (WindowsApache-MySQL-PHP) is applied. It provides a compact Internet infrastructure to work adequately. In the acronym, the Windows are very suitable for all systems, Apache is the web server, MySQL is the database manager, and PHP is the programming language. All deduced parameters were found using optimized FORTRAN programs known to be executable.

It is a typical web 2.0 interactive platform with users and profiles to upload, modify, make comments, etc., in the database. It has 5 work subsystems:

1. The user management (anonymous administrator and investigator);

2. The management of earthquakes and associated seismic records;

3. The remarks management;

4. Link and contact management;

5. The advanced searching management.

Finally, it is important to indicate the points that justify the originality of database:

1. It is completely accessible and free in the Web. As anonymous user, one can download only 10 records, but for a registered (researcher) user, limitation does not exist;

2. Forty one fields with different crossed searching records may be applied. This gives the possibility to choose alternative $I M s$ and investigate them. No other databases with these characteristics exist;

3. For researcher users with intermediate privileges, it is possible to upload/delete files from anywhere to process them in the system and add them to the database. This is something that other databases do not permit (see Figure 1);

4. The database can be maintained for different parts of the world in a simple and coordinated way.

Currently, the database is available on the Web. Additional records have been uploaded to attain the required growth level of database.

\section{Case study: Application to Spanish seismic zone (low-to-moderate magnitude); structural characterization}

One RC frame structure with eight stories was designed according to the current Spanish codes [23,24]. The structure was assumed to be built in the southern part of Spain, which is a low-to-moderate seismicity zone. A numerical model that represented this frame was developed using IDARC-2D code [25]. The analyzed frame represented the structures in the long-period range (1.0-1.5 s). The frame belonged to a building that was regular and symmetric in plan. A modal analysis was carried out and a very small difference between the structural periods for $3 \mathrm{D}$ and $2 \mathrm{D}$ configurations was observed. Hence, a 2D frame type model was utilized. The columns of each story had the same reinforcement along their height, while in the beams, the reinforcement was different at each end. For detailed data, see [26].

The building was located in Granada (Spain) on stiff to medium soil, between type II and type III. The structure was calculated with the Spanish concrete code EHE and the Spanish seismic code [22]. A Uniform Hazard Spectrum as elastic spectrum with $5 \%$ damping was applied. Following the Spanish code, only one level was used for the analysis. This design spectrum was defined for $10 \%$ in 50 years $-10 / 50 / 500 \cong$ $10 / 50 / 475-$ which corresponded to the life safety level of the seismic demand in the framework of PBEE, i.e., PBEE LS. The Spanish seismic code allows for ductility-based reduction factors ranging from 1 (no ductility) to 4 (very high ductility); in this study, the realistic value of 3 was adopted. The stresses induced by the seismic actions were determined by a spectral modal analysis, and combined with those caused by the gravity loads as established by the 
Table 1. Parameter characterization for 3 bins or different adopted $I M \mathrm{~s}$.

\begin{tabular}{cccccccc}
\hline Bin & $a_{c}(\mathrm{gal})$ & $S_{a}(\mathrm{gal})$ & $\varepsilon\left(S_{a}\right)$ & $S_{v}(\mathrm{~cm} / \mathrm{s})$ & $\varepsilon\left(S_{v}\right)$ & $M\left(M_{w}\right)$ & $\Delta(\mathrm{km})$ \\
\hline 1 & $\sqrt{ }$ & $\times$ & $\times$ & $\times$ & $\times$ & $\times$ & $\times$ \\
2 & $\times$ & $\sqrt{ }$ & $\sqrt{ }$ & $\times$ & $\times$ & $\times$ & $\times$ \\
3 & $\times$ & $\times$ & $\times$ & $\sqrt{ }$ & $\sqrt{ }$ & $\sqrt{ }$ & $\sqrt{ }$ \\
\hline
\end{tabular}

Spanish concrete code [23]. In the preliminary design with gross section (elastic), the fundamental period, $T_{1}$, was $1.10 \mathrm{~s}$ (relative modal weight of $80 \%$ ).

For the selection of records, three different bins were applied (see Table 1).

It is necessary to indicate that the structural fundamental period, $T_{1}$, was equal to $1.10 \mathrm{~s}$, but $S_{a}$ and $S_{v}$ values were obtained for $T_{1}=1 \mathrm{~s}$, as it was available in the database. However, a good approximation was considered. On the other hand, from Bin 1 to Bin 3, more exigent conditions were applied.

\subsection{Searching range parameters}

General conditions were established from the database. All records with soft soil station conditions were discarded. Only the horizontal components were included. For each parameter, only a range of values was adopted.

For Bin 1, the PGA value was used. For Bin 2 and Bin 3, the searching criterion applied was to find the records with a value of dispersion in $S_{a}$ and $S_{v}$ for $T \leq$ 2. In other words, the records were selected with $\varepsilon \leq 2$ on $T$, with $\varepsilon$ being the dispersion as defined by Baker and Cornell [19]. The amounts of records found were different for each bin. It is important to indicate that records were not scaled to the corresponding spectral level before their application and they were directly applied.

In the following, an explanation of the adopted value is provided:

- Bin 1: Only $a_{c}$ (acceleration of calculate) was adopted. From NCSE02, the value of $a_{c}=0.245 \mathrm{~g}$ $\left(240 \mathrm{~cm} / \mathrm{s}^{2}\right)$ was obtained for Granada. In the database, a range from 210 to $260 \mathrm{~cm} / \mathrm{s}^{2}$ was considered;

- Bin 2: Two parameters were used; principally, $S_{a}$ was taken from NCSE02; $S_{a}(1 \mathrm{sec})=360 \mathrm{~cm} / \mathrm{s}^{2}$ and $\varepsilon_{(S a)}=2$; the values from $S_{a(1)}=300 \mathrm{~cm} / \mathrm{s}^{2}$ to $S_{a(1)}=420 \mathrm{~cm} / \mathrm{s}^{2}$ were adopted;

- Bin 3: Four parameters were used; $M=M_{w}$ (from
5.8 to 6.5$), \Delta$ (epicentral distance) from 10 to $30 \mathrm{~km}$, $S_{v(1)}$ (pseudo velocity spectra value) from 35 to 78 $\mathrm{cm} / \mathrm{s}$, and $\varepsilon_{(S v)}=2$.

Then, from the database, the record for each bin was found. For this approach, different numbers of records were found. The records were 23,15 , and 10 for Bin 1, Bin 2, and Bin 3, respectively. All values of $S_{a}(T)$ with their average spectra are shown in Figure 2. In addition, spectral comparisons are indicated among NCSE 02, the known Ambraseys function [27], and all bins applied.

\subsection{Results of application}

The structural response (i.e., EDP - Engineering Demand Parameters) was assessed. Only the probability of collapse $\left(P_{C}\right)$ and the maximum inter-story drift ratio $\left(\Delta_{d i}\right)$ were taken into account. As it has been previously defined, this is PBEE LS level. $P_{C}$ is defined as:

$$
\begin{aligned}
P_{C} & =P(C / I M=L S) \\
& =\frac{\text { number of records that cause collapse }}{\text { total number of records applied }}
\end{aligned}
$$

$\Delta_{d i}$, the maximum value (at any floor) of the interstory drift ratio, is defined as:

$$
\Delta_{d i}=\operatorname{MAX}\left(\Delta_{d i i}\right) \quad \text { with } i=1-8 .
$$

The results are shown in Table 2 .

In Table 2, $\mu$ is the mean value and $S D$ is the standard deviation value, both in lognormal distribution. On the other hand, $\mu+S D$ and $\mu+2 S D$ allow to observe the maximum probabilistic values for $P=68 \%$ and $P=96 \%$. SEM is the Standard Error of Mean:

$$
S E M=S D /(n)^{0.5}
$$

Important conclusions may be obtained from these results. Figure 2 illustrates $S_{a}-T$ curves of

Table 2. Number of records for bins and the obtained EDP statistical results.

\begin{tabular}{ccccccc}
\hline \multirow{2}{*}{$\operatorname{Bin}$} & $\boldsymbol{n}$ & $\boldsymbol{P}_{\boldsymbol{C}}(\%)$ & $\boldsymbol{\Delta}_{\boldsymbol{d i}}(\boldsymbol{*})(\boldsymbol{\mu} \pm \boldsymbol{S D})$ & $\begin{array}{c}\boldsymbol{\Delta}_{\boldsymbol{d i}}(\boldsymbol{\mu}+\boldsymbol{S D}) \\
P=68 \%\end{array}$ & $\begin{array}{c}\boldsymbol{\Delta}_{\boldsymbol{d i}}(\boldsymbol{\mu}+\mathbf{2 S D}) \\
P=96 \%\end{array}$ & SEM \\
\hline 1 & 23 & 32.10 & $0.67 \pm 0.64$ & 1.31 & 1.95 & 0.13 \\
2 & 15 & 38.33 & $0.96 \pm 0.51$ & 1.47 & 1.98 & 0.13 \\
3 & 10 & 41.00 & $0.96 \pm 0.25$ & 1.21 & 1.46 & 0.08 \\
\hline
\end{tabular}




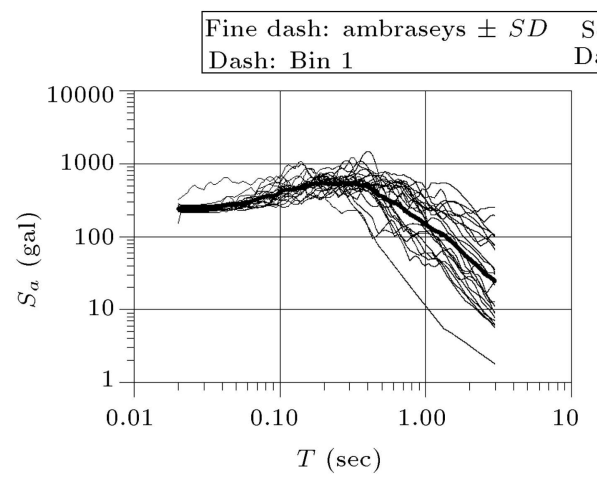

(a)

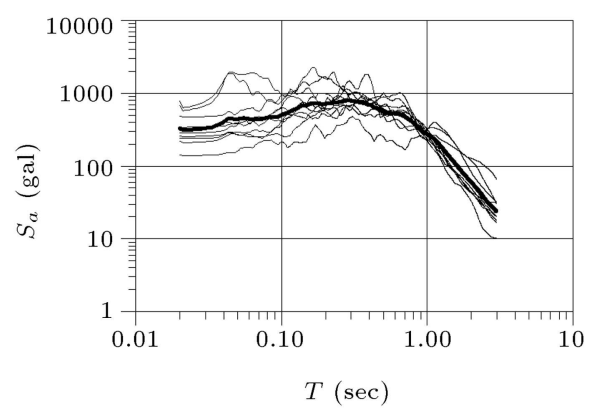

(c)

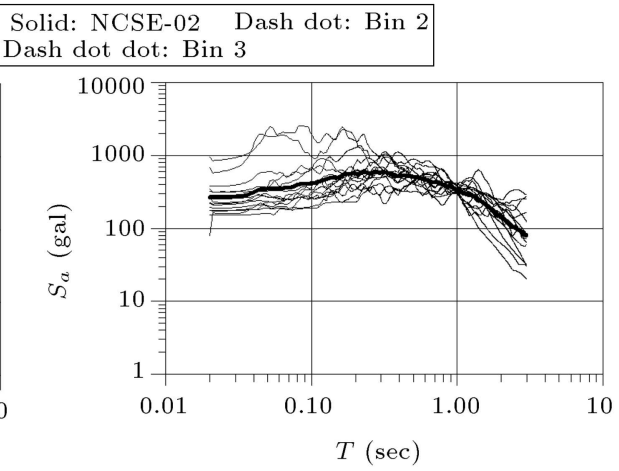

(b)

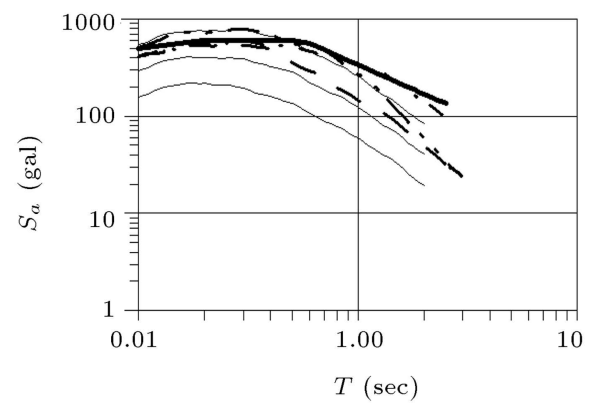

(d)

Figure 2. $S_{a}-T$ for bins and average spectrum: (a) Bin 1, (b) Bin 2, (c) Bin 3, and (d) comparison between NCSE 02 , Ambraseys function, and bins.

the 3 considered bins. The variability and distribution for each bin can be observed. It can be seen how the records adjust fairly well by applying Bin 3; therefore, the dispersion of the structural response will also decrease very much. This fact permits taking more reliable decisions.

It should be noted that for a large number of $I M \mathrm{~s}$, there will be a low quantity of records available; however, there must always be a minimal acceptable number. Through strict analysis and statistical examination of normal and log-normal distributions, it is observed that the value of $n$ which causes the lowest dispersion of the mean is around 30 . Also, note that, in general, the bigger the $I M$ quantity, the lower the dispersion at the edge of $I M-E D P$ correlation will be.

According to Table 2, in the case of Bin 1, for $I M=a_{c}\left(P_{C}=32.10 \%\right.$ and $\left.\Delta=0.67 \%\right)$, the wide dispersion of records leads to a wide dispersion of results. This results in erroneous and confusing outcomes. Although the result may seem more favorable, they can induce important errors (see the high $S D$ values). Currently, it is well known that the selection of seismic records cannot be carried out in this way. It is shown here only for comparison purposes.

An alternative implementation using $\operatorname{Bin} 3\left(P_{C}=\right.$ $41.0 \%$ and $\Delta_{d i}=0.96 \%$ ) is able to reach more reliable values. Taking into account the $S D$ values, it can be observed how even with a low number of records, the uncertainty of results can be highly reduced when starting from more realistic records.

This simple application shows the importance of an appropriate selection of records and, obviously, an adequate statistical approach for post-processing.

\section{Conclusions}

In the present paper, a new accessible online database, called SAS, is described. It has different parameters to search the most suitable records for responses history analysis of structures. This database has seismologic and engineering parameters. Generally, this combination of parameters cannot found in other databases. This seismic database is an original contribution, since it includes some deduced parameters of interest in the selection of records. The database is very useful for obtaining records for structural calculus, especially in case of PBEE analyses.

The system has a block of executable software to find engineering parameters that are not commonly easily accessible, such as normalised energy density, Fajfar-Vidic-Fischinger Index, Characteristics Index, Araya-Saragoni Index, Housner Spectrum Intensity, etc. To date, only some available data have been used and more earthquakes and records must be added.

A simple real application for searching records for seismic calculus of structures was presented. An example for low-to-moderate seismic zone in Spain 
was applied. Three different bins of $I M$ were used and the responses were compared. It was observed that a better definition of the seismic action meant a reduction in the uncertainty of results. The benefit and improvement of the use of this database is unquestionable. The database permits carrying out further investigation into $I M-E D P$ relations and new $I M$ parameters. Applied studies or future applications can be development in order to investigate the $I M$ $E D P-D M$ relations and its implications in structural calculation. Significant improvements can be possible for records by searching beyond the current practice. The investigation of different and more precise $I M \mathrm{~s}$ in the selection of records can pave the way for important improvements, especially in the field of PBEE.

Considering the database, it is necessary to highlight that: (1) It is completely accessible and free; (2) For researcher users, with intermediate privileges, it is possible to upload/delete files from anywhere to process them by the system and add them to the database; and (3) The database can be maintained for different parts of the world.

\section{Acknowledgments}

The authors gratefully acknowledge the sharing of the strong-motion catalog/database, and constructive comments of reviewers are greatly appreciated.

\section{References}

1. FEMA P695, Quantification of Building Seismic Performance Factors, Federal Emergency Management Agency, Washington, DC (2009).

2. ASCE 7-2016, Minimum Design Loads and Associated Criteria for Buildings and Other Structures, ASCE 7-16, American Society of Civil Engineers, Reston, Virginia (2016).

3. PEER. Ground Motion Database, Pacific Earthquake Engineering Research Center University of California (Berkeley) (EEUU). Available at http://ngawest2. berkeley.edu/spectras/20911/searches/new

4. IRIS, Incorporated Research Institutions for Seismology, NSF, National Science Foundation (EEUU). Available at http://www.iris.edu/hq/

5. COSMOS, Consortium of Organizations for Strong Motion Observation Systems, USGS (EEUU). Available at http://www.cosmos-eq.org/

6. CESMD, Center for Engineering Strong Motion Data (EEUU). Available at http://www. strongmotioncenter, org/vdc/scripts/adv_search.plx

7. K-NET/KIK-NET Strong-Motion Seismograph Networks, NIED. National Research Institute for Science and Disaster Prevention (Japan). Available at http://www.kyoshin.bosai.go.jp/
8. EUROSEISTEST, Euroseis Test Database, Soil Dynamics and Geotechnical Earthquake Engineering (SDGEE), Aristotle University of Tessaloniki (Greece). Available at http://euroseisdb.civil.auth.gr/

9. IESEE, Institute of Engineering Seismology and Earthquake Engineering (Greece). Available at http://www.itsak.gr/

10. SGMDT Strong Ground Motion Database of Turkiye (Turkey). Available at http://kyhdata.deprem.gov.tr/ 2K/kyhdata_v4.php

11. SWWISS NSMN, Swiss National Strong Motion Network, Swiss Seismological Service (Swiss). Available at http://www.seismo.ethz.ch/index

12. ITACA, Italian Acceleromatric Archive (version 2.0), Istituto Nazionale di Geofisica e Vulcanologia (Italy). Available at http://itaca.mi.ingv.it/ItacaNet/

13. NERA, CSEM-EMSC, European-Mediterranean Seismological Centre (Europe). Available at http://www. seismicportal.eu; http://www.emsc-csem.org

14. USGS, U.S. Geological Survey, Earthquake data Web page. Available at http://earthquake.usgs.gov/data/

15. ORFEUS-SM. European Strong Motion Database (Europe). Available at http://esm.mi.ingv.it/DYNAstage/

16. FEMA 273., NEHRP, guidelines for the Seismic Rehabilitation of Building, Federal Emergency Management Agency, Washington, DC (1997).

17. FEMA 356., Prestandard and Commentary for the Seismic Rehabilitation of Buildings, Federal Emergency Management Agency, Washington DC, SAC Joint Venture (2000).

18. FEMA 451B NEHRP. Recommended Provisions for New Building and Other Structures: Training and Instructional Materials, Federal Emergency Management Agency, Washington, DC (2007).

19. Baker, J. and Cornell, C.A. "A vector-valued ground motion intensity measure consisting of spectral acceleration and epsilon", Earthq. Eng. \& Struct. Dyn., 34, pp. 1193-1217 (2005).

20. Catalan, A. and Foti, D. "Multilevel performancebased procedure applied to moderate seismic zones in Europe", Earthq. and Struct., 8(1), pp. 57-76 (2015).

21. Zambrano, A. and Foti, D. "Damage indices evaluation for seismic resistant structures subjected to low-cycle fatigue phenomena", Int. J. of Mech. Sci., 78, pp. 106117 (2014).

22. Ambraseys, N.N., Douglas, J., Sigbjörnsson, R., Berge-Thierry, C., Suhadolc, P., Costa, G., and Smit, P.M., Dissemination of European Strong-Motion Datausing Strong-Motion Datascape Navigator, CD ROM Collection, Eng. and Physical Sci. Res. Council, United Kingdom, 2 (2004).

23. EHE., Structural Concrete Instruction [Instrucción de Hormigón Estructural (in Spanish)], Ministerio de Fomento. Madrid, Spain (2008). 
24. NCSE-02., Earthquake Resistant Construction Standard. General Part and Building [Norma de Construcción Sismorresistente. Parte General y Edificación (in Spanish)], Ministerio de Fomento. BOE No. 244, Madrid, Spain (2002).

25. Reinhorn, A.M., Kunnath, C.K., Valles, R.E., Li, C., and Madan, A., Software Idarc 2D Version 6.1. A Program for the Inelastic Damage Analysis of Buildings, SUNY, Buffalo, NY (2006). http://civil.eng.buffalo.edu/idarc2d50/

26. Catalan, A., Benavent-Climent, A., and Cahis, X. "Selection and scaling of earthquake records in assessment of structures in low-to-moderate seismicity zones", Soil Dyn. and Earthq. Eng., 30, pp. 40-49 (2010).

27. Ambraseys, N.N., Simpson, K.A., and Bommer, J.J. "Prediction of horizontal response spectra in Europe", Earthq. Eng. \& Struct. Dyn., 25, pp. 371-400 (1996).

28. Tso, W.K., Zhu, T.J., and Heidebrecht, A.C. "Engineering implications of ground motion AV ratio", Soil Dyn. and Earthq. Eng., 11(3), pp. 133-144 (1992).

29. Cabanas, L., Benito, B., and Herraiz, M. "An approach to the measurement of the potential structural damage of earthquake ground motions", Earthq. Eng. \& Struct. Dyn., 26(1), pp. 79-92 (1997).

30. Arias, A. "A measure of earthquake intensity", Seismic Design for Nuclear Power Plants, R. Hansen, Ed., Cambridge, MA: MIT Press, pp. 438-469 (1970).

31. Sarma, S.K. "Energy flux of strong earthquakes", Tectonophysics, 11, pp. 159-173 (1972).

32. Bommer, J.J. and Martinez-Pereira, A. "The effective duration of earthquake strong motion", J. of Earthq. Eng., 3(2), pp. 127-172 (1999).

33. Trifunac, M.D. and Brady, A.G. "A study on the duration of strong earthquake ground motion", Bull. of Seismological Society of America, 65, pp. 581-626 (1975).

34. Jennings, P.C., Engineering Seismology, in Earthquakes: Observation, Theory and Interpretation, $\mathrm{H}$. Kanamori and E. Boschi, Eds., Italian Phys. Soc., Milan, Italy. pp. 138-173 (1982).

35. Fajfar, P., Vidic, T., and Fischinger, M. "A measure of earthquake motion capacity to damage medium-period structures", Soil Dyn. and Earthq. Eng., 9(5), pp. 236242 (1990).

36. Park, Y.J., Ang, A.H., and Wen, Y.K. "Seismic damage analysis and damage-limiting design of reinforced concrete building", Structural Research Series, No. 516, University of Illinois (1984).

37. Araya, R. and Saragoni, G.R. "Earthquake accelerogram destructiveness potential factor", 8th World Conf. on Earthq. Eng., Earthquake Engineering Research Institute, San Francisco, CA pp. 835-842 (1985).

38. Housner, G.W. "Spectrum intensities of strong motion earthquakes", Symosium on Earthq. and Blast Effects Struct., EERI, Berkeley, CA, pp. 20-36 (1952).
39. Kappos, A.J. "Sensitivity of calculated inelastic seismic response to input motion characteristics", 4th US National Conference of Earthquake, EERI, CA, pp. 2534 (1990).

40. Von Thun, J., Roehm, L., Scott, G., and Wilson, J. "Earthquake ground motions for design and analysis of dams", Earthq. Eng. and Soil Dyn. II - Recent Advances in Ground-motion Evaluation, Geotechnical Special Publication, 20, pp. 463-481 (1988).

\section{Appendix A}

Database parameters are shown in Table A.1.

\section{Appendix B}

The database-deduced parameters are defined as follows:

- $\boldsymbol{P G A}$ : The largest absolute value of the acceleration time history $\left(\mathrm{cm} / \mathrm{s}^{2}\right)$.

- $\boldsymbol{P} \boldsymbol{G} \boldsymbol{V}$ : The largest absolute value of the velocity time history obtained by integration of the acceleration time history $(\mathrm{cm} / \mathrm{s})$.

- PGD: The largest absolute value of the displacement time history obtained by integration of the velocity time history $(\mathrm{cm})$.

- $\boldsymbol{P} \boldsymbol{A A} / \boldsymbol{P G} \boldsymbol{V}$ : Used as a seismic parameter because of its correlation with the magnitude and the epicentral distance [28]. Units in $(\mathrm{g}) /(\mathrm{m} / \mathrm{s})$ with $g=981$ $\mathrm{cm} / \mathrm{s}^{2}$.

- $\boldsymbol{C A} \boldsymbol{V}$ : Cumulative Acceleration Velocity [29] defined as the area under the absolute acceleration time history $(\mathrm{cm} / \mathrm{s})$ :

$$
C A V=\int_{0}^{t_{n}}|a(t)| . d t .
$$

- $\boldsymbol{A I}$ : Arias Intensity [30], where $g$ is the acceleration due to gravity (set to $9.80665 \mathrm{~m} / \mathrm{s}^{2}$ ) and $a(t)$ is the ground acceleration $(\mathrm{cm} / \mathrm{s})$ :

$$
A I=\frac{\pi}{2 g} \int_{0}^{t_{n}} a(t)^{2} d t .
$$

- NED: Normalized Energy Density [31], where $v(t)$ is the ground velocity. True energy density can be derived from this quantity by multiplying it by $V \rho / 4$, where $V$ is the wave velocity and $\rho$ the mass density at the recording site $\left(\mathrm{cm}^{2} / \mathrm{s}\right)$ :

$$
N E D=\int_{0}^{t_{n}} v(t)^{2} d t .
$$

$\boldsymbol{T}(\boldsymbol{t o t})$ : Total time of data acceleration (s). 
Table A.1. Database parameters.

\begin{tabular}{|c|c|c|c|c|}
\hline & & ID & Parameter & Description \\
\hline \multirow{14}{*}{  } & \multirow{8}{*}{ 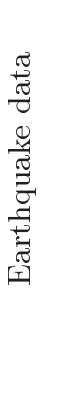 } & 1 & Name & Earthquake name \\
\hline & & 2 & Date & Earthquake date \\
\hline & & 3 & Country & Epicentral country \\
\hline & & 4 & Earth type & Mainshock, aftershock, etc. \\
\hline & & 5 & Depth & $(\mathrm{km})$ \\
\hline & & 6 & Magnitude & Value \\
\hline & & 7 & Magnitude type & Mw, Ms, etc. \\
\hline & & 8 & Fault mechanism & Reverse, normal, etc. \\
\hline & \multirow{6}{*}{ 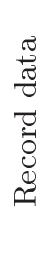 } & 9 & Source & Source-institution \\
\hline & & 10 & Station & Station name \\
\hline & & 11 & Station soil type & Rock, stiff, etc. \\
\hline & & 12 & Correction & Yes, no \\
\hline & & 13 & Component type & Long, transv., etc. \\
\hline & & 14 & Epicentral distance & $(\mathrm{km})$ \\
\hline \multirow{35}{*}{ 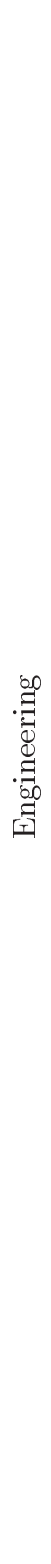 } & \multirow{35}{*}{ 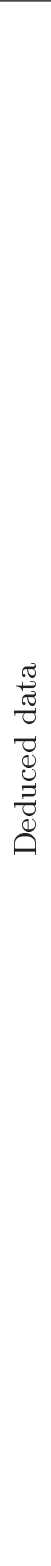 } & 15 & PGA & Peak Ground Acceleration \\
\hline & & 16 & PGV & Peak Ground Velocity \\
\hline & & 17 & PGD & Peak Ground Displacement \\
\hline & & 18 & $\mathrm{PGA} / \mathrm{PGV}$ & $(\mathrm{g}) /(\mathrm{m} / \mathrm{s})$ \\
\hline & & 19 & $\mathrm{CAV}$ & Cumulative Acceleration Velocity \\
\hline & & 20 & $\mathrm{AI}$ & Arias Intensity \\
\hline & & 21 & NED & Normalized Energy Density \\
\hline & & 22 & T total & Total time of data acceleration \\
\hline & & 23 & $\mathrm{~T}$ brack abs & Bracketed absolute duration \\
\hline & & 24 & $\mathrm{~T}$ brack rel & Bracketed relative duration \\
\hline & & 25 & $\mathrm{~T}$ sig abs & Significant absolute duration \\
\hline & & 26 & $\mathrm{~T}$ sig rel & Significant relative duration \\
\hline & & 27 & PA & Power of excitation \\
\hline & & 28 & A rms & RMS acceleration or root-mean-square acceleration \\
\hline & & 29 & I fvf & Fajfar-vidic-fischinger index \\
\hline & & 30 & Ic & Characteristics Index \\
\hline & & 31 & $\mathrm{PD}$ & Destructive Potential Index. Araya-Saragoni Index. \\
\hline & & 32 & $S_{a} \max$ & Maximum of the elastic acceleration spectrum \\
\hline & & 33 & $S_{a}(0.5)$ & Value of the elastic acceleration spectrum in $T=0.5 \mathrm{sec}$ \\
\hline & & 34 & $S_{a}(1.0)$ & Value of the elastic acceleration spectrum in $T=1.0 \mathrm{sec}$ \\
\hline & & 35 & $S_{v} \max$ & Maximum of the elastic velocity spectrum \\
\hline & & 36 & $S_{v}(0.5)$ & Value of the elastic velocity spectrum in $T=0.5 \mathrm{sec}$ \\
\hline & & 37 & $S_{v}(1.0)$ & Value of the elastic velocity spectrum in $T=1.0 \mathrm{sec}$ \\
\hline & & 38 & $S_{d} \max$ & Maximum of the elastic displacement spectrum \\
\hline & & 39 & $S_{I} \mathrm{~h}$ & Housner Spectrum Intensity \\
\hline & & 40 & $S_{I}(0.2)$ & Partial Housner Spectrum Intensity \\
\hline & & 41 & $S_{I}(0.5)$ & Partial Housner Spectrum Intensity \\
\hline & & 42 & $S_{I}(0.8)$ & Partial Housner Spectrum Intensity \\
\hline & & 43 & $S_{I}(1.0)$ & Partial Housner Spectrum Intensity \\
\hline & & 44 & $S_{I}(1.2)$ & Partial Housner Spectrum Intensity \\
\hline & & 45 & $S_{I}(1.5)$ & Partial Housner Spectrum Intensity \\
\hline & & 46 & $E / m \max$ & Elastic energy for mass unit \\
\hline & & 47 & $T(E / m \max )$ & Period value where the maximum $E / m$ is reached \\
\hline & & 48 & ASI & Acceleration Spectral Intensity \\
\hline & & 49 & WE & $\begin{array}{l}\text { Width of energy. Percentage of period scale in which } 80 \% \text { of } \\
\text { maximum } E / m \text { is reached [\%] }\end{array}$ \\
\hline
\end{tabular}


- T(brack abs): Bracketed absolute duration. Length of interval between the first and the last time the ground acceleration exceeds the value of $0.05 \mathrm{~g}$, with $g=981 \mathrm{~cm} / \mathrm{s}^{2}[32](\mathrm{s})$.

- $\boldsymbol{T}(\boldsymbol{b r a c k}$ rel): Bracketed relative duration. Length of interval between the first and the last time the ground acceleration exceeds a percentage of $50 \%$ of peak ground acceleration [32] (s).

- $\boldsymbol{T}$ (sig $\boldsymbol{a b s}$ ): Significant absolute duration. Length of interval between $0.01 \mathrm{~m} / \mathrm{s}$ and $0.125 \mathrm{~m} / \mathrm{s}$ in Arias Intensity (s) [33].

- $\boldsymbol{T}$ (sig rel): Significant relative duration. Length of interval between 5-95\% of arias intensity (s) [33].

- $\boldsymbol{P}_{\mathbf{0 9 0}}=\boldsymbol{P}_{\boldsymbol{A}}$ : Power of excitation. AI0.95 and AI0.05 are the values on Arias intensity [34]. All are taken from Husid diagram (AI in percentage) (g).

$$
\begin{aligned}
P_{090} & =P_{A}=\left(\frac{A I_{0.95}-A I_{0.05}}{T(\text { sig.rel })}\right) * \frac{2 . g}{\pi} \\
& =\frac{1}{T(\text { sig.rel })} \int_{T 0.05}^{T 0.095} a(t)^{2} d t .
\end{aligned}
$$

- Arms: RMS acceleration or Root-Mean-Square acceleration. It is the acceleration in the current acceleration units, where $t_{n}$ is the length of record and $a(t)$ is ground acceleration $\left(\mathrm{m} / \mathrm{s}^{2}\right)$.

$$
\text { Arms }=\sqrt{P_{A}}=\sqrt{\frac{1}{T(\text { sig.rel })} \int_{T 0.05}^{T 0.95} a(t)^{2} d t} .
$$

$\boldsymbol{I}_{\boldsymbol{F} \boldsymbol{V} \boldsymbol{F}}:$ Fajfar-Vidic-Fischinger Index $\left(\mathrm{cm} / \mathrm{s}^{*} \mathrm{sec}^{0.25}\right)$ [35]:

$$
I_{F V F}=P G V^{*} T(\text { sig.rel })^{0.25} \text {. }
$$

- $\boldsymbol{I}_{\boldsymbol{C}}$ : Characteristics Index $\left(\mathrm{g}^{1.5 *} \sec ^{0.5}\right)[36]$ :

$$
I_{C}=\text { Arms }^{1.5} \cdot T(\text { sig.rel })^{0.5} \text {. }
$$

- $\boldsymbol{P}_{\boldsymbol{D}}$ : Destructive potential index. Araya-Saragoni Index, where $A I$ is the maximum Arias intensity and $v_{0}$ is the intensity of zero crossings (or characteristic frequency) $\left(\mathrm{cm} / \mathrm{s}^{3}\right)[37]$ :

$$
P_{D}=\frac{A I}{v_{0}^{2}} .
$$

- Sa max: Maximum of the elastic acceleration spectrum (with $T_{\max }=3 \mathrm{sec}$ and $\left.\xi=5 \%\right)\left(\mathrm{cm} / \mathrm{s}^{2}\right)$.

- $\boldsymbol{S a}(\boldsymbol{0 . 5})$ : Value of the elastic acceleration spectrum in $T=0.5 \mathrm{sec}$ (with $T_{\max }=3 \mathrm{sec}$ and $\xi=$ $5 \%)\left(\mathrm{cm} / \mathrm{s}^{2}\right)$.

- $\boldsymbol{S a}$ (1.0): Value of the elastic acceleration spectrum in $T=1.0 \mathrm{sec}$ (with $T_{\max }=3 \mathrm{sec}$ and $\xi=$ $5 \%)\left(\mathrm{cm} / \mathrm{s}^{2}\right)$.
- $\boldsymbol{S} \boldsymbol{v}$ max: Maximum of the elastic velocity spectrum (with $T_{\max }=3 \mathrm{sec}$ and $\left.\xi=5 \%\right)(\mathrm{cm} / \mathrm{s})$.

- $\boldsymbol{S} \boldsymbol{v}(\boldsymbol{0 . 5})$ : Value of the elastic velocity spectrum in $T=0.5 \mathrm{sec}$ (with $T_{\max }=3 \mathrm{sec}$ and $\left.\xi=5 \%\right)(\mathrm{cm} / \mathrm{s})$.

- $\boldsymbol{S v}$ (1.0): Value of the elastic velocity spectrum in $T=1.0 \mathrm{sec}$ (with $T_{\max }=3 \mathrm{sec}$ and $\left.\xi=5 \%\right)(\mathrm{cm} / \mathrm{s})$.

- $\boldsymbol{S d} \boldsymbol{m a x}$ : Maximum of the elastic displacement spectrum (with $T_{\max }=3 \mathrm{sec}$ and $\xi=5 \%$ ) $(\mathrm{cm})$.

- SIH: Housner Spectrum Intensity [38] with $\xi=5 \%$,

$$
S I_{H}=\int_{0.1}^{2.5} P S V(T, \xi) d T
$$

where $\operatorname{PSV}(T, 5 \%)$ is the spectral pseudo-velocity for $5 \%$ damping and $T$ is the natural period $(\mathrm{cm})$.

- SIi: Partial Housner Spectrum Intensity, with $\xi=$ $5 \%$ and $t_{1}=0.2 T_{i}(\mathrm{~cm})$ [39]. In general:

$$
S I_{i}=\int_{T_{i}-t_{1}}^{T_{i}+t_{1}} \operatorname{PSV}(T, \xi) d T .
$$

Accordingly:

$$
\begin{aligned}
& S I_{(0.2)}=\int_{0.16}^{0.24} P S V(T, 5) d T, \\
& S I_{(0.5)}=\int_{0.40}^{0.60} P S V(T, 5) d T, \\
& S I_{(0.8)}=\int_{0.64}^{0.96} P S V(T, 5) d T, \\
& S I_{(1.0)}=\int_{0.80}^{1.20} P S V(T, 5) d T, \\
& S I_{(1.2)}=\int_{0.96}^{1.44} P S V(T, 5) d T, \\
& S I_{(1.5)}=\int_{1.20}^{1.80} P S V(T, 5) d T .
\end{aligned}
$$

$\boldsymbol{E} / \boldsymbol{m}$ : Elastic energy for mass unit $\left(\mathrm{cm}^{2} / \mathrm{s}^{2}\right)$. From the elastic velocity spectrum, from the elastic velocity spectrum, it is deduced:

$$
E / m=\frac{1}{2} \cdot S_{v}(T)^{2} .
$$

- $\boldsymbol{T}(\boldsymbol{E} / \boldsymbol{m} \boldsymbol{m a x}):$ Period value where the maximum $E / m$ is reached (s).

- ASI: Acceleration spectral intensity (cm/s) [40]:

$$
A S I=\int_{0.10}^{0.50} S A(T, 5) d t .
$$

- $\boldsymbol{W E}$ : Width of Energy. Percentage of period scale in which $80 \%$ of maximum $E / m$ is reached (\%) with $T_{\max }=3$ sec.

$$
W E=\frac{\sum T(80 \%)}{3} .100 .
$$




\section{Biographies}

Ariel Catalan is Associate Professor of Reinforced Concrete Structures, Structural Analysis of Structures, and Structural Dynamic Engineering at the University of Oviedo (Polytechnic School of Engineering of Gijon). $\mathrm{He}$ has given courses in Structural Engineering and Earthquake Engineering. Also, he has taken part in doctoral and specialist courses in seismic engineering. His subjects of interest are focused on seismic nonlinear behavior of structures, seismic databases, selection of seismic loads, and development of PBEE application. $\mathrm{He}$ is the author of over 20 scientific publications in these fields.

Dora Foti is Associate Professor of Structural Engineering at the Polytechnic of Bari. She has given courses in Structural Engineering, Earthquake Engineering, and Design of Bridges for Civil Engineering. Also, she has given lectures and seminars in numerous training courses as well as at universities and research institutes, both in Italy and outside Italy. She is the author of over 200 scientific publications in the field of Structural Engineering and Materials, in which she has mainly developed the issues related to the seismic behavior of structures, dynamic identification of historical masonry buildings, and innovative composite materials. She is and has been coordinator of several national and international scientific projects.

David Melendi is Associate Professor in the Department of Informatics at the University of Oviedo (Polytechnic School of Engineering of Gijon). He is active in Engineering Telematics and has participated in doctoral courses and seminars as a specialist professor. He is focused on modelling and simulation of Internet transference video/audio service and databases. He is the author of scientific publications in these fields and a member of different organizations, platforms, and committees, such as the SYMM (synchronized multimedia) of the W3C. 